\title{
THE ENDOPLASMIC RETICULUM OF PURKINJE NEURON BODY AND DENDRITES: MOLECULAR IDENTITY AND SPECIALIZATIONS FOR $\mathrm{Ca}^{2+}$ TRANSPORT
}

\author{
A. Villa, ${ }^{*}$ A. H. Sharp, $†$ G. Racchetti, ${ }^{*}$ P. Podini, ${ }^{*}$ D. G. Bole, $¥$ W. A. Dunn, $\S$ \\ T. POZZAN, $\|$ S. H. SNydeR $\dagger$ and J. MEldolesi ${ }^{*} \mid$ \\ *Department of Pharmacology, CNR Cytopharmacology and B. Ceccarelli Centers, S. Raffaele Scientific \\ Institute, Via Olgettina 60, 20132 Milano, Italy \\ +Departments of Neuroscience, Pharmacology and Molecular Sciences, Psychiatry and Behavioral \\ Sciences, Johns Hopkins University, School of Medicine, Baltimore, MD, U.S.A. \\ ‡Howard Hughes Medical Institute Research Laboratory, The University of Michigan Medical Center, \\ Ann Arbor, MI, U.S.A. \\ $\S$ Department of Anatomy and Cell Biology, College of Medicine, University of Florida, Gainsville, \\ FL, U.S.A. \\ $\|$ Institute of General Pathology, CNR Biomembrane Center, University of Padova, Italy
}

\begin{abstract}
Immunofluorescence and immunogold labeling, together with sucrose gradient separation and Western blot analysis of microsomal subfractions, were employed in parallel to probe the endoplasmic reticulum in the cell body and dendrites of rat cerebellar Purkinje neurons. Two markers, previously investigated in non-nerve cells, the membrane protein p91 (calnexin) and the lumenal protein BiP, were found to be highly expressed and widely distributed to the various endoplasmic reticulum sections of Purkinje neurons, from the cell body to dendrites and dendritic spines. An antibody (denominated anti-rough-surfaced endoplasmic reticulum), which recognized two membrane proteins, p14 and p40, revealed a similar immunogold labeling pattern. However, centrifugation results consistent with a widespread distribution were obtained for p14 only, while $\mathrm{p} 40$ was concentrated in the rough microsomeenriched subfractions. The areas enriched in the inositol 1,4,5-triphosphate receptor and thus presumably specialized in $\mathrm{Ca}^{2+}$ transport (stacks of multiple smooth-surfaced cisternae; the dendritic spine apparatus) also exhibited labeling for $\mathrm{BiP}$ and $\mathrm{p} 91$, and were positive for the anti-rough-surfaced endoplasmic reticulum antibody (presumably via the p14 antigen). Additional antibodies, that yielded inadequate immunocytochemical signals, were employed only by Western blotting of the microsomal subfractions, while the ryanodine receptor was studied by specific binding. The latter receptor and the $\mathrm{Ca}^{2+} \mathrm{ATPase}$, known in other species to be concentrated in Purkinje neurons, exhibited bimodal distributions with a peak in the light and another in the heavy subfractions. A similar distribution was also observed with another lumenal protein, proteine disulfide isomerase.

Taken as a whole, the results that we have obtained suggest the existence in the endoplasmic reticulum of Purkinje neurons of two levels of organization; the first identified by widespread, probably general markers (BiP, p91, possibly p14 and others), the second by specialization markers, such as the inositol 1,4,5-triphosphate receptor and, possibly, $\mathrm{p} 40$, which appear restricted to areas where specific functions appear to be localized.
\end{abstract}

Knowledge about neuron endoplasmic reticulum (ER) is still incomplete. Up until recently, most studies concentrated on the axonal reticulum, investigated because of its possible involvement in axonal transport ${ }^{29,49,50}$ and neurotransmitter release (see Ref. 11). In other regions of the neuron, only few studies have been carried out. Except for experiments revealing the distribution of glucose-6-phosphatase activity

ๆTo whom correspondence should be addressed.

Abbreviations: BSA, bovine serum albumin; EGTA, ethyleneglycolbis(aminoethylether)tetra-acetate; (R)ER, (rough-surfaced) endoplasmic reticulum; HEPES, $\mathrm{N}$-2hydroxyethylpiperazine- $N^{\prime}$-2-ethanesulfonic acid; Ins- $\mathrm{P}_{3}$ and Ins- $P_{3} R$, inositol 1,4,5-trisphosphate and its receptor; PBS, phosphate-buffered saline; PDI, protein disulfide isomerase; PMSF, phenylsulfonylfluoride; RyR, ryanodine receptor; SDS-PAGE, sodium dodecyl sulfate-polyacrylamide gel electrophoresis. in the entire $E R,{ }^{6}$ the widespread distribution of concanavalin $\mathrm{A}$ and the absence of other lectin binding, ${ }^{13,67,68}$ the information was limited to conventional electron microscopy. The latter revealed in most neurons the co-existence and occasional lumenal continuities of the rough- and smoothsurfaced sections of the ER in the cell body up to the dendrite stalk(s). Moreover, the smooth ER was shown to be distributed along the dendrites, up to the tips and (where present) the spines, giving rise to a complex tridimensional network of tubules and longitudinal cisternae. Whether at all these sites the ER expresses common molecular markers or includes highly specialized areas, designed to match the structural and functional specializations of the various regions of the cell, is still largely unknown.

Recently, interest in these problems has greatly increased in view of the possible key involvement of 
the ER in the control of intracellular $\mathrm{Ca}^{2+}$ homeostasis (for reviews, see Refs $37,38,41$ ). A role of at least part of the system as a dynamic $\mathrm{Ca}^{2+}$ store had already been envisaged in the seventies ${ }^{14.21}$ and was proposed again more recently, ${ }^{22.42}$ based on both morphological and biochemical results. The application of neurons of $\mathrm{Ca}^{2+}$ microprobe analysis ${ }^{2}$ and high resolution immunocytochemistry ${ }^{35.40 .44 .51 .53}$ has focused attention on three specific regions: (i) the spine apparatus, which expresses numerous receptors for the $\mathrm{Ca}^{2+}$ release second messenger, inositol 1,4,5trisphosphate $\left(\right.$ Ins- $\mathrm{P}_{3}$ ), ${ }^{40.53}$ and where $\mathrm{Ca}^{2+}$ uptake and release was observed following stimulation; ${ }^{2}$ (ii) stacks of parallel, evenly spaced smooth cisternae, whose membranes were shown to be highly enriched with Ins- $P_{3}$ receptors (Ins- $P_{3} R$ ) $)^{44,53,54}$ (iii) a population of vacuoles (calciosomes) containing high concentrations of specific, low-affinity high-capacity $\mathrm{Ca}^{2+}$ storage protein(s). ${ }^{60,62,64}$

Most of these recent studies were carried out in Purkinje neurons of the cerebellum which, compared to the other neurons, are particularly enriched with these and also with other markers of $\mathrm{Ca}^{2+}$ stores: the $\mathrm{Ca}^{2+} \mathrm{ATPase}^{24,39,48}$ and the ryanodine receptor (RyR), a second intracellular $\mathrm{Ca}^{2+}$ channel that is apparently distributed differently from the Ins-P, R. ${ }^{17.66}$ Because of these properties, and because of their well-known architecture, ${ }^{45}$ Purkinje neurons are a particularly interesting model for the molecular characterization of the ER. In the present study immunocytochemistry has been employed in combination with subcellular fractionation to try to reveal the distribution of various ER markers, believed to be either of general occurrence or specialized for $\mathrm{Ca}^{2+}$ stores.

\section{EXPERIMENTAL PROCEDURES}

Rats (male, $200 \mathrm{~g} \mathrm{b.w.)} \mathrm{were} \mathrm{killed} \mathrm{by} \mathrm{decapitation} \mathrm{and}$ cerebella rapidly collected. For morphological experiments they were immediately immersed in the fixative ( $4 \%$ formaldehyde $-0.25 \%$ glutaraldehyde in $125 \mathrm{mM}$ phosphate buffer, pH 7.4 and $4^{\circ} \mathrm{C}$ ) then thoroughly sliced to yield small tissue cubes and thin $(1 \mathrm{~mm})$ slices including Purkinje cell bodies and dendrites. Additional rats were killed by perfusion with the above fixative. ${ }^{53}$ Fixation was pursued for $2 \mathrm{~h}$ after which the samples were either processed for conventional electron microscopy (postfixation in $2 \% \mathrm{OsO}_{4}$ followed by dehydration, block staining and Epon embedding; see Ref. 60) or used to prepare cryosections for immunocytochemistry, as described below. For cell fractionation experiments, three to five cerebella were immersed in ice-cold $0.32 \mathrm{M}$ sucrose, $5 \mathrm{mM}$ HEPES-KOH, pH 7.4, $0.1 \mathrm{mM}$ phenylsulfonylfluoride (PMSF), minced with razor blades and homogenized in $10 \mathrm{ml}$ of the same solution using a glass Dounce homogenizer (loose-fitting pestle, 30 up and down strokes).

\section{Immunofiuorescence}

Samples fixed as described above were processed for the preparation of cryosections as described in Ref. 60 . Sections approximately $15 \mu \mathrm{m}$ thick were cut with a conventional cryostat, flattened over glass slides and covered with $2 \%$ liquid gelatin in phosphate buffer. After a short treatmen with $1 \% \mathrm{Na}$ borohydrate, they were washed and exposed for $30 \mathrm{~min}$ to a normotonic solution containing $0.3^{\circ} \%$ Triton $\mathrm{X}-100,15 \%$ filtered goat serum, $0.45 \mathrm{M} \mathrm{NaCl}$, and $10 \mathrm{mM}$ phosphate buffer, $\mathrm{pH} 7.4$. After washing, the sections were exposed $\left(1 \mathrm{~h}\right.$ at $37^{\circ} \mathrm{C}$ or overnight at $4^{\circ} \mathrm{C}$ ) to either one of the various primary antibodies, to non-immune antibodies (all diluted in the Triton X-100-goat serum-containing solution) or to the solution alone. Sections were then washed again thoroughly and treated with the appropriate rhodamine-labeled goat antibodies $(1: 20-1: 40$ in the Triton $X-100$-goat serum solution, $30-60 \mathrm{~min}, 37 \mathrm{C}$ ), washed again, and mounted in glycerol in he examined in a 7eis Photomicroscope III apparatus. Optical sections were obtained using a confocal scanning microscope (series MRC-600; BioRad Laboratories). Digital images stored on optical disc were photographed with a Lasergraphic LFR camera.

\section{Immunogold labeling}

Samples fixed as described above were processed for the preparation of ultrathin cryosections $(50-100 \mathrm{~nm})$ as described in detail elsewhere. ${ }^{60}$ Sectioning was carried out in a Reichert Jung (Vienna, Austria) Ultracut ultramicrotome equipped with an $\mathrm{FC}_{4}$ apparatus. Cryosections were collected over nickel grids and covered with $2 \%$ gelatin. After treatment with $125 \mathrm{mM}$ phosphate buffer, pH 7.4 , supplemented with $0.1 \mathrm{M}$ glycine, they were exposed to the first antibody (diluted in phosphate glycine buffer) for $1 \mathrm{~h}$ at $37^{\circ} \mathrm{C}$, then washed with phosphate-glycine buffer and decorated with anti-IgG (rabbit or rat)-coated gold particles $(5 \mathrm{~nm}$, dilution $1: 80$ in the same buffer). For dual-labeling the rabbit anti-Ins- $P_{3} R$ polyclonal antibodies were applied together with the anti-BiP monoclonal antibodies, and the same was eventually done for the large $(15 \mathrm{~nm}$, coated with antibodies anti-rabbit IgGs) and small ( $5 \mathrm{~mm}$, coated with antibodies anti-rat IgGs) gold particles. The immunodecorated grids were then washed and processed as recommended in Ref. 26. Cryosections were examined in a Hitachi $\mathrm{H}-7000$ electron microscope. Pictures were usually taken at $\times 24,000$ magnification. In order to establish background levels, control cryosections were processed without exposure to the first antibody. The gold particle density $\left(n / \mu \mathrm{m}^{2}\right)$ values measured in these preparations $(2.5$ and 6.5 with small and large gold) were similar to those counted over structures of the experimental cryosections not recognized by the antibodies employed (nuclei. mitochondria)

\section{Subcellular fractionation}

Cerebellar tissue homogenates were first centrifuged at 11,000 r.p.m. For 10 min in a Beckman JA20 rotor. The pellet was carefully resuspended in the homogenization solution and spun again as above. The two supernatants were combined and centrifuged at 36,000 r.p.m. for 60 min in the Beckman 50.2Ti rotor. The pellet (total microsomes) was resuspended in the homogenization solution. Twelve to fifteen milligrams of protein was loaded on top of a $11.0-\mathrm{ml}$ linear $(0.3-1.9 \mathrm{M})$ sucrose gradient in buffer $A$, and centrifuged at 23,000 r.p.m. overnight in a Beckman SW41 rotor. Eleven $1-\mathrm{ml}$ subfractions were collected from the bottom of the centrifuge tube and their protein concentration was measured. Then the subfractions were diluted drop by drop with ice-cold water to $0.32 \mathrm{M}$ sucrose. The resulting samples were centrifuged at 60,000 r.p.m. for $60 \mathrm{~min}$ in the Beckman TL 100 ultracentrifuge, and the ensuing pellets were either fixed in situ and processed for conventional electron microscopy as described above, or resuspended to yield samples with $0.5 \mathrm{mg} / \mathrm{ml}$ protein concentration. These samples were used for biochemical assays, sodium dodecyl sulfate-polyacrylamide gel electrophoresis (SDS-PAGE) and Western blot analysis. 
Sodium dodecyl sulfate-polyacrylamide gel electrophoresis and Western blotting

SDS-slab gel electrophoresis was carried out as described in Ref. 63 on $5-10 \%$ polyacrylamide gradient minigels. High transfer of proteins onto nitrocellulose membranes (blots) was carried out at $220 \mathrm{~mA}$ for $16-18 \mathrm{~h}$ in a buffer containing $25 \mathrm{mM}$ Tris, $192 \mathrm{mM}$ glycine, $\mathrm{pH} 8.3$, and $20 \%$ methanol.

Western blots. Blots were processed at room temperature, first with phosphate-buffered saline (PBS) containing 3\% bovine serum albumin (BSA) for $60 \mathrm{~min}$, then for $60 \mathrm{~min}$ with antibodies dissolved in PBS containing $1 \%$ BSA and $0.05 \%$ Tween 20 . After washing four times for $5 \mathrm{~min}$ with PBS, $0.2 \%$ Tween 20 , they were incubated for $60 \mathrm{~min}$ with either anti-(rabbit Ig) or anti-(mouse Ig) IgGs conjugated with alkaline phosphatase, that were then revealed by staining with 5-bromo-4-chloro-3-indolyl phosphate and nitro blue tetrazolium. Densitometry of the relevant antigen bands of immunoblots was carried out using an LKB chromatoscanner CS-380.

\section{Biochemical assays}

$\left[{ }^{3} \mathrm{H}\right]$ Ryanodine binding. $0.5 \mathrm{mg}$ of microsomal protein was incubated in a medium containing $1 \mathrm{M} \mathrm{KCl}, 10 \mathrm{mM}$ HEPES, pH 7.4, $150 \mu \mathrm{M} \mathrm{CaCl} 20.1 \mathrm{mM}$ EGTA; $2 \mathrm{mM}$ dithiotreitol, 0.1 mM PMSF, $550 \mu \mathrm{M}$ ATP and $4 \mathrm{nM}$ $\left[{ }^{3} \mathrm{H}\right]$ ryanodine, in the absence and presence of $10 \mu \mathrm{M}$ ryanodine for total and non-specific binding, respectively. After $30 \mathrm{~min}$ at $37^{\circ} \mathrm{C}$, samples were filtered on $0.45-\mu \mathrm{M}$ Millipore filters, which were rinsed with $10 \mathrm{ml}$ of ice-cold $1 \mathrm{M} \mathrm{NaCl}, 10 \mathrm{mM}$ HEPES, pH 7.4, then dried and counted for radioactivity. Under these conditions, unspecific binding accounted for approximately $35 \%$ of the total recovered counts. The $K_{d}$ of the specific binding, measured independently in total microsomes, was $6.1 \mathrm{nM}$.

Protein. Protein was determined by the BCA procedure (Pierce, Rockford, III., U.S.A.) and RNA by a UV method following sequential perchloric acid extraction of membrane subfractions.

\section{Materials}

The following antibodies employed here have been described elsewhere: anti-Ca ${ }^{2+}$ ATPase (a rabbit polyclonal against a fusion protein between the $E$. coli type protein and the rabbit slow twitch cardiac enzyme ${ }^{33}$ ) anti-p91 and anti-rough-surfaced endoplasmic reticulum (RER) (affinity purified) (rabbit polyclonals against liver ER vesicles ${ }^{15,32}$ ); anti-BiP (a rat monoclonal against the purified protein ${ }^{s}$ ); anti-PDI (a rabbit polyclonal against the $\mathrm{C}$ terminal KDDD sequence, the KDDD antibody ${ }^{59}$ ). Of the two antibodies against the Ins- $P_{3} R$, the affinity-purified rabbit polyclonal was described in Ref. 47; the monoclonal was developed in the laboratory by injecting the foot-pad of female balb/c mice with the $C$ terminal 21 amino acid peptide of the receptor coupled to keyhole hemocyanin and suspended in complete Freund's adjuvant. Lymphocytes of popliteal lymphnodes were fused with cells of the $13 \times 63$ line and cells were cloned once by limited dilution. The antibodies produced as ascites were partially purified by ammonium sulfate precipitation. The anti-calbindin antibody was purchased from Boehringer; $\left[{ }^{3} \mathrm{H}\right]$ ryanodine from New England Nuclear; rhodamine-labeled anti-rabbit and rat IgGs from Technogenetics (Milan, Italy); and 5- and 15-nm colloidal gold particles, coated with goat IgGs against either rabbit (large and small particles) or rat (small particles only) IgGs from Biocell (Cardiff, U.K.). The fine chemicals employed in this work were reagent grade, purchased from Sigma, St Louis MO, U.S.A.

\section{RESULTS}

Western blots of total rat cerebellar microsomes, probed with the antibodies employed in the present
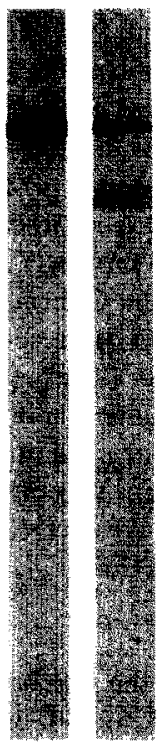

(1)

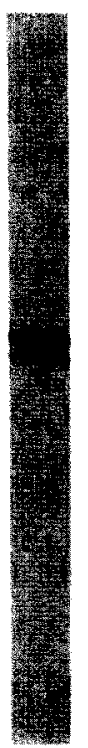

23

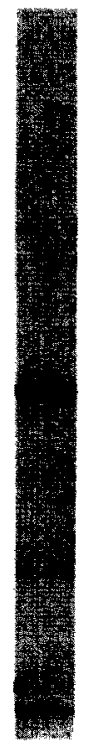

(4)

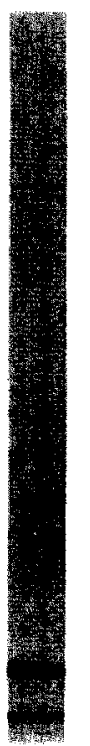

(5)

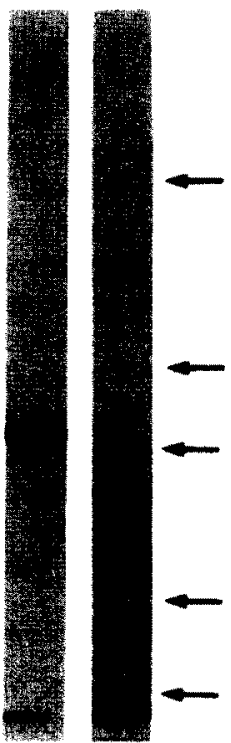

(6)

7
Fig. 1. Western blots of total cerebellar microsomes probed with the antibodies employed in the present work. Fifty micrograms of protein were applied to each lane of an SDS polyacrylamide gradient $(5-15 \%)$ gel. Arrows to the right indicate the position of markers: from the top (in mol.wt $\left.\times 10^{-3}\right) 200,97.4,69,46$ and 30 . Lanes 1 and 2 concern the Ins- $P_{3} R$ (poly and monoclonal antibodies, respectively); lane 3, the $\mathrm{Ca}^{2+}$ ATPase; lanes 4 and 5, the ER membrane proteins (anti-p91 and anti-RER antibodies, respectively); lanes 6 and 7, the ER lumenal proteins (anti-BiP and anti PDI antibodies, respectively). Encircled numbers indicate the antibodies employed also for immunocytochemistry.

work are shown in Fig. 1. Of the two anti-Ins- $P_{3} R$ antibodies, the first, an affinity-purified rabbit polyclonal antibody, ${ }^{47}$ recognized only the receptor (apparent mol.wt, 260,000 mol.wt lane 1) whereas the second (a mouse monoclonal antibody against the C-terminal, 21 amino acid sequence) also recognized an additional band, of approximately 185,000 mol.wt, lane 2. Anti-Ca ${ }^{2+}$ ATPase (a rabbit polyclonal antibody against a fusion protein of $E$. coli tr $\mathrm{pE}$ and rabbit slow-twitch cardiac $\mathrm{Ca}^{2+}$ ATPase, Ref. 33) labeled a doublet approximately 99,000 and 105,000 mol. wt. (lane 3). Lanes 4 and 5 show blots decorated with rabbit polyclonal antibodies against purified liver rough microsome membranes. The first $t^{30,32,57}$ was initially reported to recognize four (apparent mol.wt $\times 10^{-3}: 29,58,66$ and 91) major microsomal bands of rat kidney cells. In the cerebellum, the slowest migrating of these bands was heavily decorated (Fig. 1, lane 4), while faint bands at approximately 66,000 and 29,000 mol.wt appeared only when staining of the blot was prolonged (not shown). From here on this antibody will be indicated as anti-p91. The second antibody was affinity-purified by binding to stripped RER vesicles from rat liver (anti RER). ${ }^{15}$ Two of the bands recognized in liver microsomes were also revealed in the cerebellum: the 
40,000-mol.wt band visible in Fig. I, lane 5 as well as a band of 14,000 mol. wt running at the front in that Figure (see Fig. 5). The last two antibodies (lanes 6 and 7) were against proteins resident in the ER lumen, BiP and protein disulfide isomerase, protein disulfide isomerase (PDI), revealed by a rat monoclonal antibody (single band of 78,000 mol. wt) and a rabbit polyclonal antibody against the $\mathrm{C}$-terminal peptide sequence $(55,000 \mathrm{~mol}$. wt band), respectively. ${ }^{5.59}$ of the antibodies shown in Fig. 1, only four (lane numbers encircled) yielded adequate responses when employed for immunocytochemistry (immunofluorescence and immunogold labeling). The others were therefore employed only for Western blot analysis of microsomal subcellular fractions.

\section{Immunocytochemistry}

Our studies were concentrated on the cerebellar cortex, with special interest for the Purkinje cell body and dendrites. No specific attention was dedicated to the axons in the cerebellar white matter of the folia and cerebellar medulla and to the deep cerebellar nuclei, where Purkinje neuron projections are addressed.

Immunofluorescence. In Fig. 2 the immuno decoration patterns obtained in thick (approx. $15 \mu \mathrm{m}$ ) cryosections of the cerebellar cortex by the use of the four antibodies described above (panels B-E) are compared with those obtained with a commercial antibody against a $\mathrm{Ca}^{2+}$ binding protein, calbindin (panel A), known to be uniformly distributed throughout the cytosol of Purkinje cells, ${ }^{8,17.18}$ Panels $F-L$ are confocal images of dendrites and spines taken from the same preparations of the adjacent conventional immunoffuorescence panels. As can be seen, the general pattern obtained with the anti-Ins$P_{3} R$ antibody (panel $B$ ) resembled that with anti-calbindin (panel $\mathrm{A}$ ), with marked labeling of both the cell body cytoplasm and the dendritic tree. Clear differences, however, emerged by the confocal analysis of dendrites. With the anti-calbindin antibody the spines appeared in fact numerous, large and in direct continuity with the dendritic shafts (panel F), whereas with the anti-Ins- $P_{3}$ antibody they usually appeared as smaller, highly fluorescent dots, often separated from the shafts (panel $G$ ). This result suggests that Ins- $P_{3} R$-rich membranes are concentrated within the head rather than within the spine stalk. At variance with Purkinje neurons, and in agreement with previous studies ${ }^{35,40,51,53}$ the other cells of the cerebellar cortex appeared unlabeled for the

Fig. 2. Purkinje cell immunofluorescence. Left panels exhibit low-power, conventional images of the neuronal cell bodies and dendrites; right panels confocal, high-power images of the dendritic tree. Panels $A$ and $F$ were obtained with anti-CB, $B$ and $G$ with anti Ins- $P_{3} R, C$ and $H$ with anti $p 91$, $D$ and $I$ with anti-RER, $E$ and $L$ with anti-BiP antibodies. Scale bar in $\mathrm{A}=20 \mu \mathrm{m}$ and applies to panels $\mathrm{A}-\mathrm{E}$; scale bar in $F=20 \mu \mathrm{m}$ and applies to panels $\mathrm{F} L \mathrm{~L}$.
Ins- $P_{3} R$. The two antibodies against ER membrane proteins, anti-p91 and anti-RER antibodies (pancls C, $H$ and $D, I)$ yielded similar, yet distinguishable.
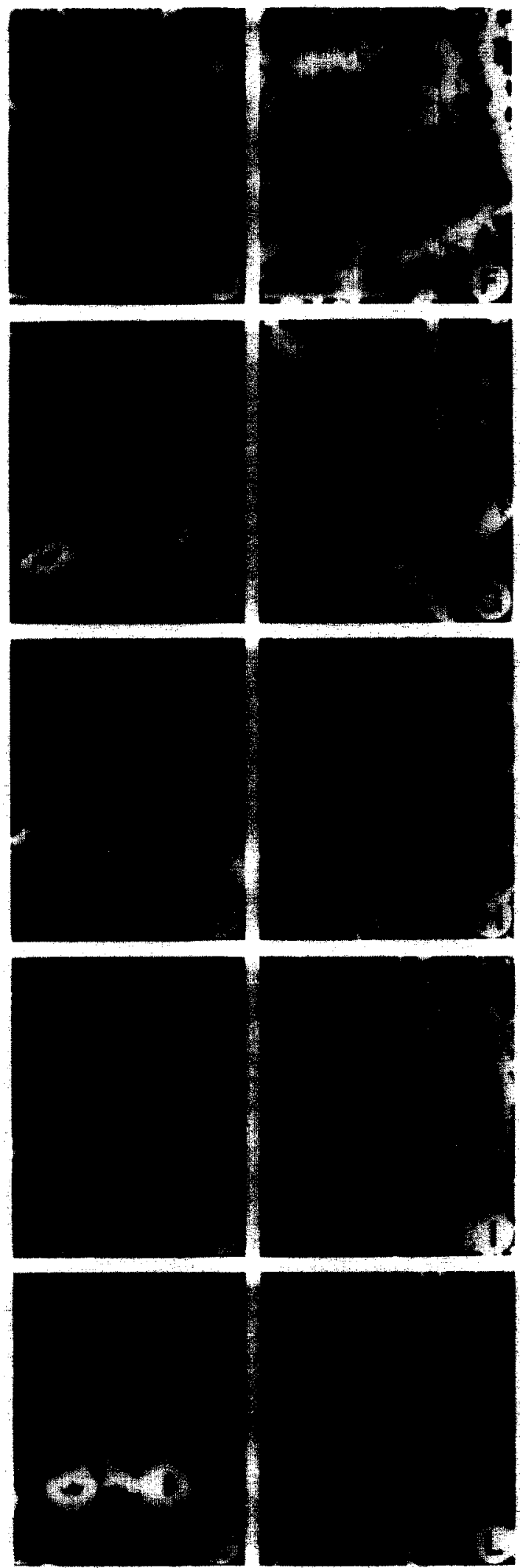
patterns. With both antibodies labeling was not restricted to Purkinje neurons but also occurred in cells of the granular (mostly granule neurons) and molecular (stellate and basket neurons) layers. ${ }^{45}$ The cytoplasm of the Purkinje neuron body showed a widespread, although non-uniform, labeling. In the dendritic tree, the labeling with the anti-p9l antibody, although less intense than with anti-calbindin and anti-Ins- $P_{3} R$ antibodies, showed up clearly even in the conventional image (panel C), whereas with the anti-RER antibody the signal was distinctly weaker than in the cell body and did not show up above the adjacent structures unless at the level of large dendrites (panel D). In the confocal images, however, the dendrite shafts were revealed by both antibodies (panels $\mathrm{H}$ and I). Smaller structures distributed among dendritic shafts were probably accounted for by both dendritic spines and parallel fibers. Finally, the BiP pattern (panels $E$ and $L$ ) resembled closely that observed with the anti-p 91 antibody, except for the relatively stronger signal in the Purkinje cell body, and for the dendritic spines often also immunopositive in their stalks, showing their continuity to the dendritic tree.

Immunogold. Ultrathin cryosections were studied after labeling with either a single or two antibodies. Organelles moderately positive for BiP were observed within cells and axons of the whole cerebellar cortex, particularly in the granular layer and also within terminals impinging onto Purkinje dendritic spines in the molecular layer (not shown). Stronger labeling was however concentrated in Purkinje neurons, within the lumen of most elements of the entire ER, from the rough-surfaced cisternae of the cell body (not shown) to the longitudinal and tubular elements of dendrites (Fig. 3 A,B), up to the spine apparatus. In contrast, nuclei, mitochondria, the Golgi complex and its adjacent large granules as well as multivesicular bodies appeared BiP-negative. By dual labeling, the two ER portions known (see Refs $44,45,54)$ to be Ins- $P_{3} R$-rich, i.e. cisternal stacks distributed in both the Purkinje cell body and the dendrites (Fig. 3A) and the spine apparatus (not shown) were always found to also be labeled for BiP, and the same occurred for most of the other ER elements, both rough and smooth-surfaced, labeled to a lower degree for the receptor (inset in Fig. 3A and not shown). In contrast, appreciable Ins- $\mathrm{P}_{3}$ labeling was revealed by only approximately $50 \%$ of the profiles positive for BiP.

With the antibodies against the two membrane markers (anti-p91 and anti-RER), immunogold particles were localized at the ER lumenal surface, especially over filaments protruding into the lumen. The general distribution revealed by the anti-p91 antibody resembled that with $\mathrm{BiP}$ in both the cell body and dendrites, i.e. labeling was evident on most rough-surfaced (Fig. 3B) and smooth-surfaced (not shown) ER cisternae and not on the other organelles. With the anti-RER antibody, labeling was stronger on the rough-surfaced cisternae of the body (Fig. 3C) than on the smooth cisternae and tubules of dendrites (not shown). Moreover, with both markers labeling was observed over typical cisternal stacks known to be Ins-P ${ }_{3} R$-rich (insets in Fig. 3B, C), irrespective of the cell area of localization.

\section{Subcellular fractionation}

Microsomal subfractions were isolated by equilibrium continuous sucrose gradient centrifugation and analysed for marker distribution by Western blotting. In the same subfractions the RyR, for which no adequate antibody is available to us, was studied by a specific binding assay. The isolated subfractions were also sedimented as pellets, fixed and studied by conventional electron microscopy. The protein distribution and the concentration of RNA and RyR, calculated on a protein basis in the microsomal subfractions is illustrated in Fig. 4. The bulk of the microsomes was recovered in the intermediate 5-9 subfractions of the gradient, whereas RNA exhibited the expected high concentration in the heavy subfractions (Fig. 4A, B). Morphologically, the proteinrich subfractions were found to contain primarily smooth-surfaced vacuoles and tubules of various internal electron density, whereas subfractions 10 and 11 exhibited rough-surfaced elements and free ribosomes (not shown). The RyR, on the other hand, was distributed along the gradient with two reproducible peaks, one in the light region (rich in membrane sheets and cisternae, not shown), the other in the heavy region (Fig. 4B). Ins- $P_{3} R$, revealed by Western blotting (Fig. 5), appeared rather uniformly distributed from subfractions 3 to 11 . On the other hand, bimodal distribution, with peaks in both the heavy and the light microsomes and lower concentrations in the intermediate fractions was observed with other markers (Fig. 5). $\mathrm{Ca}^{2+}$ ATPase was concentrated especially in two very light subfractions, 2 and 3, and also showed an enrichment in the heavy subfraction 10. The ER membrane protein $\mathrm{p} 91$ and the lumenal protein PDI were enriched in subfractions 3-5 and 9-11, while the second lumenal protein, BiP, was more concentrated in the heavy region (peak in subfraction 10) but also showed considerable labeling of the intermediate and of the light subfraction 3 (Fig. 5). Only with the last two markers was a clear divergence from the bimodal distribution observed. In fact, p185 (the protein cross-labeled by our monoclonal antibody against the Ins- $P_{3} R$ ) was recovered in the intermediate 4-8 subfractions. Of the proteins recognized by the anti-RER antibody, one (p40) was indeed concentrated in the RNA-enriched subfractions 10 and 11 , while p14 was widely distributed, from subfraction 4 to 11 .

\section{vISCUSSION}

In the present study, two classical approaches of cell biology, immunocytochemistry and subcellular 

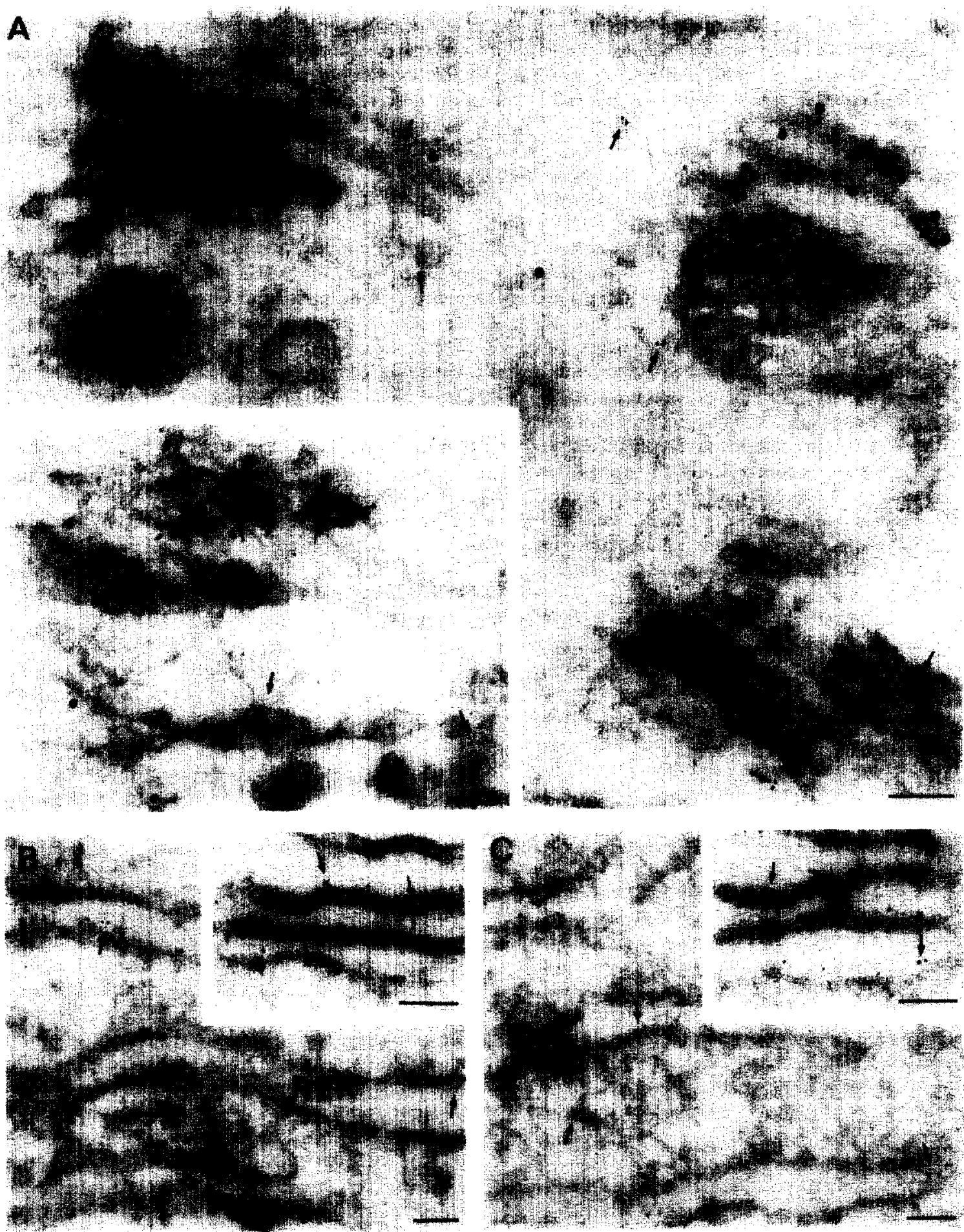

Fig. 3. Immunogold labeling of Purkinje neuron ultrathin cryosections. In all panels arrows mark small gold particle? immunolabeling. A shows dual immunolabeling with anti-Ins- $P_{3} R$ and anti-BiP antibodies (large and small gold particles, respectively). In the main panel three stacks (st) composed of various smooth-surfaced cisternae located in a dendrite are heavily labeled by Ins- $P_{3} R$-addressed large gold particles distributed over, or in the proximity of the closely apposed membranes. The small gold particle immunolabeling of BiP is concentrated over both the clear lumena of the stacked cisternae and adjacent smooth-surfaced vesicles and tubules. Two mitochondria $(\mathrm{M})$ are negative for both markers. Inset of $A$ shows the smooth-surfaced ER network of another dendrite. The large gold Ins-P $R$ labeling is sparse and restricted to the lower, irregular cisterna, whereas other cisternae and tubules appear negative. Small gold particle clusters labeling BiP are contained within the lumena of both Ins- $\mathbf{P}_{3} R$-positive and negative cisternae. Panel ' $B$ illustrates the $p 91$ immunolabeling in two parallel-running RER cisternae and a cisternal stack of the cell body. Notice that the label is concentrated at the lumenal surface of the membranes, particularly over filamentous structures protruding into the lumen. Panel $C$ illustrates the labeling with the anti-RER antibodies. The field resembles that of panel $B$ (three rough ER cisternae and a cisternal stack in the inset) and the immunolabeling is also similar, except that in the stack the gold particles are more clustered. Scale bars in all panels $=0.1 \mu \mathrm{m}$. 

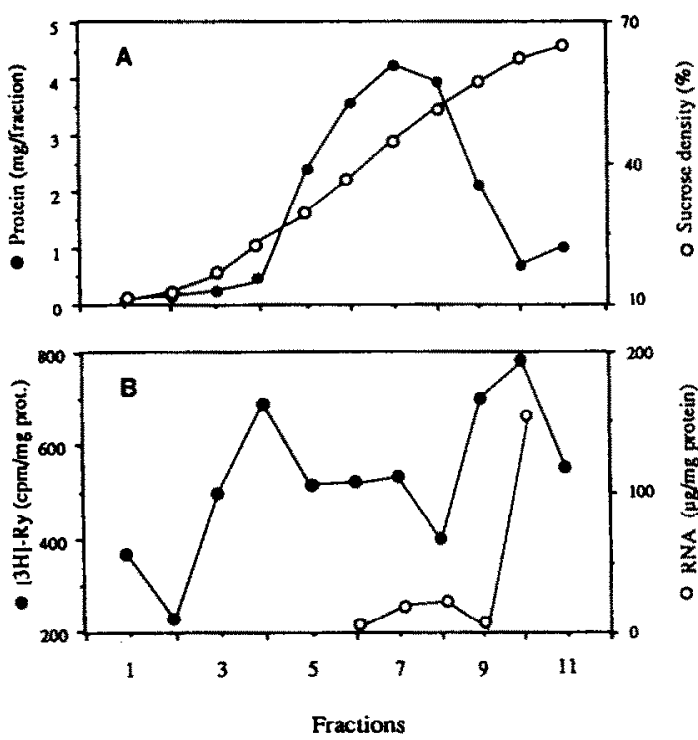

Fig. 4. Distribution of protein, specific ryanodine (Ry) binding and RNA among the subfractions obtained by equilibrium centrifugation of cerebellar microsomes over a continuous $15-50 \%$ sucrose gradient.

fractionation, have been employed in parallel to investigate the distribution of various ER markers. While immunocytochemistry could be precisely focused on Purkinje neurons (cell body and dendrites), easily recognized because of their large size and peculiar morphology, subcellular fractions were by necessity obtained from the entire cell population of the cerebellum. In spite of their small number, and because of their large size and richness in ER, Purkinje neurons are expected to also contribute considerably to the subfractionation results, especially in terms of Ins- $\mathrm{P}_{3} \mathrm{R}, \mathrm{Ca}^{2+}$-ATPase and
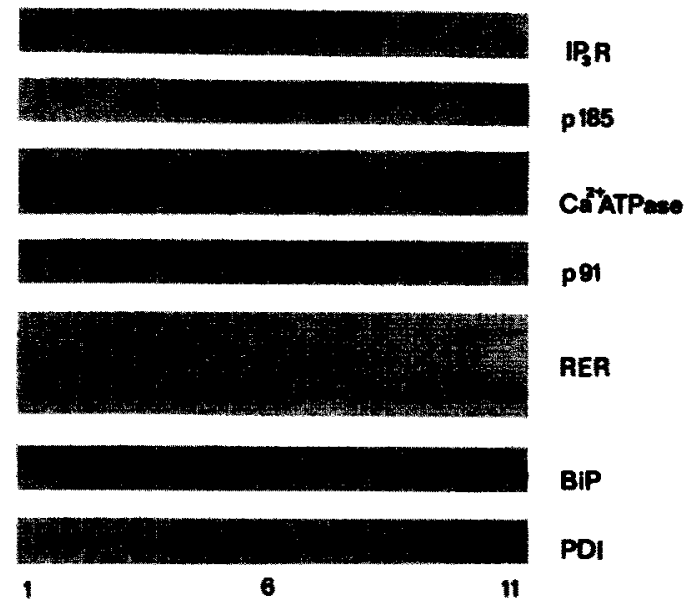

Fig. 5. Western blots of the microsomal subfractions decorated with the antibodies against the antigens indicated to the right. Fifty micrograms protein/subfraction were applied to gels prepared and processed as in Fig. 1. Each strip illustrates labeling of a single antigen except for that marked RER, where both the p40 and pl4 antigens are shown. Subfraction numbers are shown at the bottom.
RyR, which are highly concentrated in this cell type. ${ }^{17,24,35,39,40,48,60}$ It should be emphasized, however, that the subfractions contained unspecified amounts of subcellular particles originated from other neurons and glia. Thus, the results obtained by this approach cannot be attributed with any certainty to Purkinje neurons unless confirmed by the immunocytochemical data.

\section{Molecular markers of the neuronal endoplasmic reticulum}

Up until now, the assignment to the ER of membrane-bound structures expressed by neurons has been based primarily on conventional electron microscopy, particularly on the gross membrane morphology and apparent lumenal continuity of the various ER sections. Most biochemical analyses have not yielded clear results due to the heterogeneity of the nervous tissues and the ensuing problems of subcellular fractionation (see above). The only enzyme cytochemical study reported so far documented a widespread distribution of a single activity, glucose-6-phosphatase. ${ }^{6}$ In our previous studies on chicken Purkinje neurons, a widespread distribution of the ER lumenal protein, BiP, had already been observed but not studied in detail. ${ }^{60}$ This result is now confirmed in the rat and extended to the p9l ER membrane marker, which has recently been shown to bind $\mathrm{Ca}^{2+}$ and for which the name of calnexin has thus been proposed. ${ }^{65}$ This protein had been investigated previously only in non-nerve tissues and cells, and is believed to be localized in the rough-surfaced cisternae only ${ }^{30,32,57,65}$ where it might be involved in the binding of lumenal proteins via $\mathrm{Ca}^{2+}$ bridges. ${ }^{65}$ Both BiP and p91 were found, however, to be widely distributed in the ER elements of the Purkinje cell body and dendrites, independently of their being rough- or smooth-surfaced, and were never observed in other organelles. These two proteins may thus be considered as the first molecularly identified general ER markers of a neuron. A widespread distribution is also likely for the other ER lumenal protein, PDI, investigated, however, only by subcellular fractionation, with recovery in both the heavy and light microsomal subfractions. Within ER elements, common markers apparently co-exist with specialized markers, such as the major, $\mathrm{p} 40$ antigen recognized by the anti-RER membrane antibody,${ }^{15}$ which was recovered only with the rough-surfaced microsome. Even this antibody, however, decorated the smooth ER, possibly by recognizing an additional, smaller (p14) antigen which was found in both the rough and smooth ER subfractions of the gradient. Thus, this antibody cannot be considered as fully RERspecific as previously proposed in hepatocytes. ${ }^{15}$ Preliminary immunofluorescence experiments were carried out to probe the differential distribution of p 40 and p14 by the use of specific, affinity purified antibodies, without success. On the other hand, $\mathrm{Ca}^{2+}$ ATPase was concentrated especially in very light 
microsomal subfractions, with detectable levels in the intermediate and, especially, in those enriched in rough-surfaced vesicles. In Western blots the encyme appeared as a doublet, suggesting the expression in the rat cerebellum of two isoforms of similar mol.wt., a situation previously observed in non-nerve tissues and cells $\mathrm{s}^{20,33.46}$ and recently reported in the cerebellum of the pig. ${ }^{48}$ The last protein revealed in our blots. pl 85 recognized by the monoclonal antibody against the Ins- $P_{3} R$, was apparently absent from the rough microsomes and recovered only in the intermediate subfractions of the gradient. Since, however, the antibody was not adequate for immunocytochemistry, we do not know whether this antigen is indeed concentrated in the smooth ER or if it is expressed by cells other than Purkinje neurons that are poor in the rough and rich in the smooth ER.

\section{Resident proteins of the endoplasmic reticulum lumen: what is their function?}

Interest about $\mathrm{BiP}$ and PDI has focused on their function in post-translational modification, prevention of stress-induced aggregation, quality control and conformational adjustment of secretory and other lumenal proteins addressed to the Golgi complex. ${ }^{19.52}$ Interaction of BiP with membrane proteins has also heen reported, however only during chain elongation and in the case of misfolding of the intralumenal domains. ${ }^{3,34,43}$ Because of such a molecular assistance function, BiP has been grouped together with other non-ER proteins under the general name of chaperones. ${ }^{16.19}$ So far, the possible occurrence of these proteins within the smooth ER has been given limited attention except for a few studies in hepatocytes, lymphocytes and the tumoral, adrenocorticotrophic hormone secreting cell line AtT-20, ${ }^{1,456}$ In the latter work BiP and PDI were shown to be present throughout the entire ER, up to the tip of neurites. Our results demonstrate that BiP is localized throughout the entire ER lumen in Purkinje neurons. This opens the problem of the function of this protein at considerable distances away from the rough ER and the Golgi complex, where its target proteins are synthesized and transported. A conventional chaperone function of $\mathrm{BiP}$ in dendrites and spines is hard to envisage unless a fraction of the segregated proteins in transit along the ER-Golgi pathway is diverted to dendrites, possibly by simple overflow along the ER system. Other functions of BiP and PDI, e.g. assistance to either membrane proteins which need continuous control and adjustment in their lumenal domains, or lumenal proteins translocated post translationally (for yeast, see Refs 10,12,59), although conjectural, cannot be excluded at the present time.

\section{$\mathrm{Ca}^{2+}$ stores}

New information has recently been gathered regarding the cytological nature of intracellular $\mathrm{Ca}^{2+}$ stores in Purkinje neurons. Stacks of parallel smooth-surfaced ER cisternae, separated from each other by evenly spaced bridges (lamellar bodics). were already described in these neurons in the sixites but considered at that time a fixation artifact ${ }^{2058}$ (sec, however, Ref 28). We and others ${ }^{44,53,54}$ have demonstrated that these structures are not only present in specimens fixed by a variety of procedures, but also greatly (over 10-fold) enriched in Ins- $P_{3} R$ compared to the rest of the ER. .4.57.54 $^{\text {The accumulation of }}$ cisternal stacks composed of molecularly specialized membrancs is not unique to Purkinje neurons but has also been observed in Chinese hamster ovary (UT-1) cells over-expressing the rate-limiting enzyme of cholesterol synthesis, 3-hydroxy, 3-methylglutaryl CoA reductase (christalloid ER). ${ }^{27}$ An artifactual sorting of individual proteins to yield specialized membranes appears unlikely. In contrast, the reverse artifact, i.e. the disassembly of multicisternal stacks to yield a population of smooth-surfaced elements during improper fixation, has been demonstrated in neuronal growth cones."

Our present results have revealed a new property of the Ins- $P_{3} R$-rich stacked membranes: their specialization is not absolute inasmuch as their membranes express the general ER markers, p91 and probably also p14. This observation confirms, at a molecular level, previous conclusions on the ER nature of these structures based on their lumenal continuity with rough-surfaced cisternae. ${ }^{44,5354}$ The presence of BiP within their lumen has been reported in chicken Purkinje neurons. ${ }^{60}$ However, in the previous study dual Ins- $P_{3} R-B i P$ experiments were not carried out and therefore direct proof of the co-existence of the two proteins could not be given. ${ }^{60}$ All the general ER markers (p91, pl4 and BiP) were found to also be expressed in the spine apparatus, another structure rich in Ins- $\mathbf{P}_{3} \mathbf{R}{ }^{40,53,66}$ Because of this latter and other known properties (observed however in the chicken: exclusion of calsequestrin and $R y R^{17,60.66}$ ) the spine apparatus is suggested to be specialized for transient Ins- $\mathbf{P}_{3}$-triggered $\mathrm{Ca}^{2+}$ release responses (for discussion, see Ref. 38).

Within Purkinje neurons, the Ins- $P_{3} R$ is not restricted to the highly enriched regions discussed so far but is also expressed, although at much lower concentrations, by many conventional ER elements, rough-(including the nuclear envelope) and smoothsurfaced. ${ }^{40,44,51,53}$ This distribution might explain the widespread recovery of the Ins- $P_{3} R$ along the sucrose gradient, from subfractions 3 to 11 . The organization of cisternal stacks and spine apparatus was dismantled by homogenization. Thus, these Ins- $P_{3} \mathbf{R}$-rich structures could not be identified by conventional electron microscopy of the subfractions.

A final mention concerns the RyR. Immunocytochemistry of chicken Purkinje neurons has revealed a selective distribution of RyR to some ER cisternae, ${ }^{66}$ while subcellular fractionation has suggested localization in a population of small vacuoles (calciosomes $^{62}$ ), characterized by the high concentration of 
the low-affinity high-capacity $\mathrm{Ca}^{2+}$ binding protein, calsequestrin, and the low concentration of BiP within their lumen..$^{\text {to }}$ The bimodal distribution of the RyR binding revealed by sucrose gradient centrifugation of rat cerebellar microsomes might be consistent with such a dual distribution. In the Purkinje neurons of the rat the major low-affinity highcapacity $\mathrm{Ca}^{2+}$ binding protein is not calsequestrin but a protein recognized by anti-calreticulin antibodies (Villa $e t$ al., unpublished observations) so far, the intracellular distribution of this protein has not been investigated. Therefore calciosomes have not been identified in these cells, and their relationship to the ER is still unclear (discussion, see Ref. 38). The existence of separate stores endowed with either Ins- $P_{3} R$ or $R y R$ has been documented from the functional point of view in various types of neurons, ${ }^{41.55}$ including Purkinje neurons. ${ }^{7}$ The search for the RyR-specific store therefore remains open.

\section{CONCLUSION}

The results we have reported identify a group of widespread, probably general markers of the ER in cerebellar Purkinje neurons, as well as particular aspects of the ER subcompartments specialized in
$\mathrm{Ca}^{2+}$ transport. These specialized ER regions could be expressed at different levels and be differently localized within the various neurons. Such a conclusion is already supported by results in a variety of cells, including cerebellar granule neurons, where $\left[\mathrm{Ca}^{2+}\right]_{\mathrm{i}}$ responses sustained by Ins- $\mathrm{P}_{3}$ have been observed $^{41}$ even if the level of the Ins- $P_{3} R$ is so low as to be undetectable by immunocytochemistry. ${ }^{40,44,53}$ Moreover, in retinal neurons, in contrast to the widespread distribution of Purkinje neurons, an impressive concentration of the Ins- $\mathrm{P}_{3} R$ in the presynaptic compartment has recently been reported. ${ }^{47}$

Acknowledgements - The generous gift of the anti-p91, anti$\mathrm{Ca}^{2+}$ ATPase and anti-PDI antibodies (by D. Louvard, Pasteur Institute, Paris, J. Lytton and D. MacLennan, Univ. of Toronto and S. Fuller, EMBL, Heidelberg) is gratefully acknowledged. We are grateful to $\mathbf{R}$. Longhi for the preparation of the Ins- $P_{3} R \quad C$ terminal peptide-keyhole hemocyanin complex. We thank Lorella Di Giorgio for skilful secretarial assistance and Dr S. Tacchetti of BioRad for the assistance in the use of the confocal microscope. This work was supported by a CNR grant, Target Project Biotechnology and Bioinstrumentation (to J.M.), a CNR fellowship (to P.P.), the USPHS MH-18501, Research Scientist Award DA-00074 (to S.H.S.), and the postdoctoral fellowship MH-09953 (to A.H.S.).

\section{REFERENCES}

1. Akagi S., Yamamoto A., Yoshimori T., Masaki R., Ogawa R. and Tashiro Y. (1988) Distribution of protein disulfide isomerase in rat hepatocytes. J. Histochem. Cytochem. 36, 1533-1542.

2. Andrews S. B., Leapman R. D., Landis D. M. D. and Reese T. S. (1988) Activity-dependent accumulation of calcium in Purkinje cell dendritic spines. Proc. natn. Acad. Sci. U.S.A. 85, 1682-1685.

3. Blount P. and Merlie J. P. (1991) BiP associates with newly synthesized subunits of the mouse muscle nicotinic receptor. J. Cell Biol. 113, 1125-1132.

4. Bole D. G., Hendershot L. M. and Kearney J. F. (1986) Posttranslational association of immunoglobulin heavy chain binding protein with nascent heavy chains in nonsecreting hybridomas. J. Cell Biol. 102, 1558-1566.

5. Bole D. G., Dowin R., Doriaux M. and Jamieson J. D. (1989) Immunocytochemical localization of BiP to the rough endoplasmic reticulum: evidence for protein sorting by selective retention. J. Histochem. Cytochem. 37, $1817-1823$.

6. Broadwell R. D. and Cataldo A.M. (1983) The neuronal endoplasmic reticulum: its cytochemistry and contribution to the endomembrane system. I. Cell bodies and dendrites. J. Histochem. Cytochem. 31, 1077-1088.

7. Brorson J. R., Bleakman D., Gibbons S. J. and Miller R. J. (1992) The properties of intracellular $\mathrm{Ca}^{2+}$ stores in cultured rat cerebellar neurons. $J$. Neurosci. (in press).

8. Celio M. (1990) Calbindin, D-28K and parvalbumin in the rat nervous system. Neuroscience 35, 375-475.

9. Cheng T. P. O. and Reese T. S. (1985) Polarized compartmentalization of organelles in growth cones from developing optic tectum. J. Cell Biol. 101, 1473-1480.

10. Chirico W. J., Waters M. G. and Blobel G. (1988) $70 \mathrm{~K}$ heat stock related proteins stimulate protein translocation into microsomes. Nature 332, 805-810.

11. De Camilli P. and Jahn R. (1990) Pathways to regulated exocytosis in neurons. A. Rev. Physiol. 52, 625-685.

12. Deshaies R. J., Koch B. D., Werner-Washburne M., Craig E. A. and Schekman R. (1988) A family of stress proteins facilitaters translocation of secretory and mitochondrial precursor polypeptides. Nature 332, 800-805.

13. Dontenwill M., Roussel G. and Zanetta J. P. (1985) Immunohistochemical localization of a lectin-like molecule, R1, during the postnatal development of the rat cerebellum. Brain Res. 349, 245-252.

14. Duce I. R. and Keen P. (1978) Can neuronal smooth endoplasmic reticulum function as a calcium reservoir? Neuroscience 3, 837-848.

15. Dunn W. A. Jr (1990) Studies on the mechanisms of autophagy: formation of the autophagic vacuole. J. Cell Biol. 110, 1923-1933.

16. Ellis R. J. and van Der Vies S. M. (1991) Molecular chaperones. A. Rev. Biochem. 60, 321-347.

17. Ellisman M. H., Deerinck T. J., Ouyang Y., Beck C. F., Tanksley S. J., Walton P. D., Airey J. A. and Sutko J. L. (1990) Identification and localization of ryanodine binding proteins in the avian central nervous system. Neuron 5 , 135-146.

18. Endo T., Kobayashi S. and Onaya T. (1985) Parvalbumin in rat cerebrum, cerebellum and retina during postnatal development. Neurosci. Lett. 60, 279-282.

19. Gething M.-J. and Sambrook J. (1992) Protein folding in the cell. Nature 355, 33-45.

20. Gunteski-Hamblin A.-M., Greeb J. and Shull G. E. (1988) A novel $\mathrm{Ca}^{2+}$ pump expressed in brain, kidney, and stomach is encoded by an alternative transcript of the slow-twitch muscle sarcoplasmic reticulum Ca-ATPase gene. J. biol. Chem. $263,15,032-15,040$. 
21. Henkart M. P., Reese T. S. and Brinley F. J. Jr (1978) Endoplasmic reticulum sequesters calcium in the squid giant axon. Science 202, 1300-1303.

22. Henkart M. (1980) Identification and function of intracellular calcium stores in axons and cell body neurons. Fedn Proc 39, $2783-2789$.

23. Herndon R. M. (1964) Lamellar bodies, an unusual arrangement of the granular endoplasmic reticulum. $J . c^{\prime} / l$ Biol. 20, 338-342.

24. Kaprielian Z., Campbell A. M. and Fambrough D. M. (1989) Identification of a Ca ${ }^{2+}$-ATPase in cerebellar Purkinje cells. Molec. Brain Res. 6, 55-60.

25. Karlsson U. and Schultz R. L. (1966) Fixation of the central nervous system for electron microscopy by aldehyde perfusion. III. Structural changes after exsanguination and delayed perfusion. I. Ultrastruct. Res. 14, 47-63.

26. Keller G. A., Tokuyasu K. T., Dutton A. H. and Singer S. J. (1984) An improved procedure for immunoeleciron microscopy: ultrathin plastic embedding of immunolabeled ultrathin frozen sections. Proc. natn. Acad. Sci. U.S.A. 81, $5744-5747$

27. Kochevar D. T. and Anderson R. G. W. (1987) Purified crystalloid endoplasmic reticulum from UT- 1 cells contains multiple proteins in addition to 3-hydroxy, 3-methylglutaryl coenzyme A reductase. J. biol. Chem. 262, 10321-10326.

28. Le Beux J. (1972) Subsurface cisterns and lamellar bodies: particular forms of the endoplasmic reticulum in the neurons. Z. Zellforsch. 133, 327-352.

29. Lindsey J. D. and Ellisman M. H. (1985) The neuronal endomembrane system. III. The origins of the axoplasmic reticulum and discrete axonal cisternae at the axon hillock. $J$. Neurosci. 5, 3135-3144.

30. Lippincott-Schwartz J., Donaldson J. G., Schweizer A., Berger E. G., Hauri H. P., Yan L. C. and Klausner R. D. (1990) Microtubule dependent retrograde transport of proteins into the ER in the presence of brefeldin A suggests an ER recycling pathway. Cell $60,821-836$.

31. Lipscombe D., Madison D. V., Poenie M., Reuter H., Tsien R. W. and Tsien R. Y. (1988) Imaging of cytosolic Ca ${ }^{2+}$ transients arising from $\mathrm{Ca}^{2+}$ stores and $\mathrm{Ca}^{2+}$ channels in sympathetic neurons. Neuron $1,355-365$.

32. Louvard D., Reggio H. and Warren G. (1982) Antibodies to the Golgi complex and rough endoplasmic reticulum. J. Cell Biol. 92, 92-107.

33. Lytton J. and MacLennan D. H. (1988) Molecular cloning of cDNAs from human kidney coding for two alternatively spliced products of the cardiac $\mathrm{Ca}^{2+}$-ATPase gene. J. biol. Chem. 263, 15,024-15,031.

34. Machamer C. E., Doms R. W., Bole D. G., Helenius A. and Rose J. K. (1990) Heavy chain binding protein recognizes incompletely disulfide-bonded forms of vesicular stomatitis virus $\mathrm{G}$ protein. J. biol. Chem. 265, 6879-6883.

35. Maeda N., Niinobe M., Inoue $Y$. and Mikoshiba K. (1989) Developmental expression and intracellular location of $P_{4(1)}$ protein characteristic of Purkinje cells in the mouse cerebellum. Devl Biol. 133, 67-76.

36. McBurney R. N. (1984) Role for microsomal Ca storage in mammalian neurones? Nature 309, $158-160$.

37. Meldolesi J., Madeddu L. and Pozzan T. (1990) Intracellular $\mathrm{Ca}^{2+}$ storage organelles in non muscle cells: heterogeneity and functional assignment. Biochim. biophys. Acta 1055, 130-140.

38. Meldolesi J., Villa A., Volpe P. and Pozzan T. (1992) Cellular sites of IP action. In Inositol Polyphosphates and $\mathrm{Ca}^{2+}$ (ed. Putney J. W.). Raven Press, New York

39. Michelangeli F., Di Virgilio F., Villa A., Podini P., Meldolesi J. and Pozzan T. (1991) Identification, kinetic properties and intracellular localization of the $\mathrm{Ca}^{2+}-\mathrm{Mg}^{2+}$ ATPase from the intracellular stores of chicken cerebellum. Biochem. $J .275,555-561$

40. Mignery G. A., Sudhof T. C., Takei K. and De Camilli P. (1989) Putative receptor for inositol 1,4,5-trisphosphate similar to ryanodine receptor. Nature 342, 192-195.

41. Miller R. I. (1992) The control of neuronal $\mathrm{Ca}^{2+}$ homeostasis. Prog. Neurobiol. (in press).

42. Neering I. R. and McBurney R. N. (1984) Role for microsomal Ca storage in mammalian neurones? Nature 309, $158-160$.

43. Nguyen T. H., Law D. T. S. and Williams D. B. (1991) Binding protein BiP is required for translocation of secretory proteins into the endoplasmic reticulum in Saccharomyces cerevisiae. Proc. natn. Acad. Sci. U.S.A. 88, $1565-1569$

44. Otsu H., Yamamoto A., Maeda N., Mikoshiba K. and Tashiro Y. (1990) Immunogold localization of inositol 1,4,5-trisphosphate ( InsP $_{3}$ ) receptor in mouse cerebellar Purkinje cells using three monoclonal antibodies. Cell Struct. Funct. 15, 163-173.

45. Palay S. and Chan-Palay V. (1974) Cerebellar Cortex: Cytology and Organization, p. 348. Springer, Berlin.

46. Papp B., Enyedi A., Kovacs T., Sarkadi B., Wuytack F., Thastrup O., Gardos G., Bredoux R., Levy-Toledano S. and Enouf J. (1991) Demonstration of two forms of calcium pumps by thapsigargin inhibition and radioimmunoblotting in platelet membrane vesicles. J. biol. Chem. 266, 14,593-14,596.

47. Peng Y. W., Sharp A. H., Snyder S. H. and Yau K. W. (1991) Localization of the inositol 1,4,5-trisphosphate receptor in synaptic terminals in the vertebrate retina. Neuron 6, 525-531.

48. Plessers L., Eggermont J. A., Wuytack F., Casteels R. (1991) A study of the organelle Ca ${ }^{2+}$ transport ATPase isoenzymes in pig cerebellar neurons. J. Neurosci. 11, 650-656.

49. Quataker J. (1981) The axonal reticulum in neurons of the superior cervical ganglion of the ral is a direct extersion of the Golgi apparatus. Histochem. J. 13, 109-124.

50. Rambourg A. and Droz B. (1980) Smooth endoplasmic reticulum and axonal transport. J. Neurochem. 35, 16-25.

51. Ross C. A., Meldolesi J., Milner T. A., Satoh T., Supattapone S. and Snyder S. H. (1989) Inositol 1,4,5-trisphosphate receptor localized to endoplasmic reticulum in cerebellar Purkinje neurons. Nature 339, 468-470.

52. Rothman J. E. (1989) Polypeptide chain binding proteins: catalysts of protein folding and related processes in cells. Cell 59, 591-601

53. Satoh T., Ros C. A., Villa A., Supattapone S., Pozzan T., Snyder S. H. and Meldolesi J. (1990) The inositol 1,4,5-trisphosphate receptor in cerebellar Purkinje cells quantitative immunogold labeling reveals concentration in an ER subcompartment. J. Cell Biol. 111, 615-624.

54. Takei K., Metcalf A., Mignery G., Volpe P., Sudhof T. and De Camilli P. (1990) Ca' ${ }^{+}$stores in Purkinje cells: localization of Ins-P receptor and calsequestrin. Soc. Neurosci. Abstr. 16 (Part II), 1233.

55. Thayer S. A., Hirning L. D. and Miller R. J. (1988) The role of caffeine-sensitive calcium stores in the regulation of the intracellular free calcium concentration in rat sympathetic neurons in vitro. Molec. Pharmac. 34, 664-673. 
56. Tooze J., Hollinshead M., Fuller S. D., Tooze S. A. and Huttner W. B. (1989) Morphological and biochemical evidence showing neuronal properties in AtT-20 cells and their growth cones. Eur. J. Cell Biol. 49, 259-273.

57. Tougard C., Louvard D., Picart R. and Tixier-Vidal A. (1984) The rough endoplasmic reticulum and the Golgi apparatus visualized using specific antibodies in normal and tumoral prolactin cells in culture. J. Cell Biol. 96, 1197-1207.

58. Van Nimwegen D. and Sheldon H. (1966) Early postmortem changes in cerebellar neurons of the rat. J. Ultrastruct. Res. 14, 36-46.

59. Vaux D. J., Tooze J. and Fuller S. (1990) Identification by anti-idiotype antibodies of an intracellular membrane protein that recognizes a mammalian endoplasmic reticulum retention signal. Nature 345, 495-502.

60. Villa A., Podini P., Clegg D. O., Pozzan T, and Meldolesi J. (1991) Intracellular $\mathrm{Ca}^{2+}$ stores in chicken Purkinje neurons: differential distribution of the low affinity-high capacity $\mathrm{Ca}^{2+}$ binding protein, calsequestrin, of $\mathrm{Ca}^{2+} \mathrm{ATPase}$ and of the ER lumenal protein, BiP J. Cell Biol. 113, 779-791.

61. Vogel J. P., Misra L.M. and Rose M. D. (1990) Loss of BiP/GRP78 function blocks translocation of secretory proteins in yeast. $J$. Cell Biol. 110, 1885-1895.

62. Volpe P., Krause K. H., Hashimoto S., Zorzato F., Pozzan T., Meldolesi J. and Lew D. P. (1988) "Calciosome", a cytoplasmic organelle: the inositol 1,4,5-trisphosphate-sensitive $\mathrm{Ca}^{2+}$ store of nonmuscle cells? Proc. natn. Acad. Sci. U.S.A. 85, $1091-1095$.

63. Volpe P., Alderson-Lang B. H., Madeddu L., Damiani E., Collins J. H. and Margreth A. (1990) Calsequestrin, a component of the inositol 1,4,5-trisphosphate-sensitive $\mathrm{Ca}^{2+}$ store of chicken cerebellum. Neuron 5, 713-721.

64. Volpe P., Villa A., Damiani E., Sharp A. H., Podini P., Snyder S. H. and Meldolesi J. (1991) Heterogeneity of microsomal $\mathrm{Ca}^{2+}$ stores in chicken Purkinje neurons. Eur. molec. Biol. Org. J. 10, 3183-3189.

65. Wada I., Rindress D., Cameron P. H., Ou W.-J., Doherty II J.-J., Louvard D., Bell A. W., Dignard D., Thomas D. Y. and Bergeron J. J. M. (1991) SSRa and associated calnexin are major calcium binding proteins of the endoplasmic reticulum membrane. J. biol. Chem. 266, 19,599-19,610.

66. Walton P. D., Airey J. A., Sutko J. L., Beck C. F., Mignery G. A., Sudhof T. C., Deerinck T. J. and Ellisman M. H. (1991) Ryanodine and inositol trisphosphate receptors coexist in avian cerebellar Purkinje neurons. J. Cell Biol. 113, $1145-1157$

67. Wood J. G., McLaughlin B. J. and Barber R. P. (1974) The visualization of concanavalin A binding sites in Purkinje cell somata and dendrites of rat cerebellum. J. Cell Biol. 63, 541-549.

68. Wood J. G., Byrd F. I. and Gurd J. W. (1981) Lectin cytochemistry of carbohydrates on cell membranes of rat cerebellum. J. Neurocytol. 10, 149-159. 